\title{
Markowitz Portfolio Model: Evidence from Dhaka Stock Exchange in Bangladesh
}

\author{
Mokta Rani Sarker ${ }^{1}$ \\ ${ }^{1}$ (School of Business, University of Information Technology \& Sciences, Bangladesh)
}

\begin{abstract}
The main purpose of this paper is to construct an optimal portfolio by using Markowitz model. For this purpose the monthly closing prices of 164 companies listed in Dhaka Stock Exchange (DSE) and DSE all share price index for the period of July 2007 to June 2012 have been considered. The proposed method formulates an efficient set, selects portfolio having excess return to standard deviation ratio satisfying the constraint that the sum of proportions invested in the assets equals one. The optimum portfolio consists of twenty stocks selected out of 164 stocks, giving the return of 6.48\%. The findings of this paper will be useful for policy makers, all kinds of investors, corporations and other financial market-participants.
\end{abstract}

Keywords- Return, Standard Deviation, Efficient Set, Optimum Portfolio, Markowitz Model.

\section{Introduction}

It's an intricate task of selecting good investments by considering the trade-off between risk and return along with the combination of various types of investments for the investors. A rational investor always seeks to minimize risks and maximize returns on his investment in an optimal portfolio. For this purpose investors ought to maximize the level of return at a given level of risk and alternatively to minimize the level of risk at a given level of return. This is done through the construction of portfolio of assets which is subject to the investor's portfolio. Although the majority of the studies were carried out in developed countries, only a limited number of studies were conducted in developing countries. The study attempts to find out the optimal portfolio using Markowitz model.

\subsection{Problem Statement}

The problem statement for this research is to find out a single combination with the lowest volatility in monthly return over the preceding period given a population of securities.

\subsection{Objectives of the Study}

The study has been conducted to construct an optimal portfolio using Markowitz Model considering no short-sales. In addition, short-sales are not allowed in Bangladesh. And the study has been conducted on individual securities listed in Dhaka Stock Exchange (DSE). The objectives of this study are:

a. Risk-return analysis of individual securities listed in DSE.

b. Construct optimal portfolio using Markowitz Model.

c. Whether Markowitz Model performs well in DSE as well as Bangladesh Stock Market or not.

d. Assist investors in portfolio selection process to make the right choice.

\subsection{Structure of the Paper}

The text is divided into six parts: Part One, 'Introduction', introduces the importance of trade-off between risk and return. Hence, background of the problem was given briefly in this part; followed by Problem Statement, Objectives of the Study of this research. Part Two, 'Literature review', has been executed in two phases; it discusses, firstly, overview of Dhaka Stock Exchange; secondly, portfolio Analysis. Part Three, 'Methodology and Data', explains data source and methodology. Part Four, 'Data Analysis and Findings', discusses the results of the study. As the result of the study calculated by portfolio risk and return calculation, the presenting of data in the findings part is considered easier to understand. Part Five, 'Conclusion', concludes the research result as well as the limitation of the research. Part Six, 'References', provide the lists of full bibliographical details and their journal titles.

\subsection{Overview of Dhaka Stock Exchange (DSE)}

\section{Literature Review}

235 companies traded on DSE until June 2012. In 2010-2011, the volume of trade of listed securities increased by manifold at the Dhaka Stock Exchange. In 2010-2011, a total of 1969 crore and 52 lakh securities were traded on the Dhaka Stock Exchange, the value of which stands at Tk. 3 lakh 25 thousand 915 crore. On the other hand, 1012 crore and 84 lakh securities were traded in 2009-10, the value of which was Tk. 256,349 
crore. The number of trading days was 240 days in 2010-2011, which was 244 days in 2009-2010. The average number of securities traded was 8.20 crore in 2010-2011 and average transaction was Tk. 1357 crore 98 lakh. On the other hand, 4.15 crore securities were traded in 2009-2010 and average transaction was Tk. 1050 crore and 61 lakh. DSE's all-share price index was 5160.05 points at the year ended on June 30, 2010 which lost 66.86 points and stood at 5093.19 points on June 30, 2011. The DSE's all-share price index stood highest 7383.94 points on December 5, 2010. Nine new companies were listed at the DSE during 2010-11 raising the number of listed companies to 232.

In addition, The DSE's market capitalization to GDP ratio was 41.10 percent at the year ended on June 30, 2011. Collecting tax at source on share transaction from its member companies, the Dhaka Stock Exchange deposited Tk. 325.91 crore in fiscal year 2010-2011 and Tk. 128.17 crore in fiscal year 2009-2010, to the government exchequer.

\subsection{Portfolio Analysis}

Varian (1993) succinctly reviewed the history of modern portfolio theory as Markowitz's groundbreaking research on portfolio optimization was published in March 1952 in an article titled 'Portfolio Selection' in the Journal of Finance. [1]

Markowitz H. (1952 and 1959) affirmed the major assumption of the Markowitz's approach to portfolio analysis is that investors are basically risk-averse. This means that investors must be given higher returns in order to accept higher risk. Markowitz then developed a model of portfolio analysis. The three highlights of this model are normally; the two relevant characteristics of a portfolio are its expected return and some measure of the dispersion of possible returns around the expected return; rational investors will be chosen to hold efficient portfolios, those that maximize expected returns for a given level of risk or, alternatively, minimize risk for a given level of return. [3] Markowitz (1952) and Tobin (1958) showed that it was possible to identify the composition of an optimal portfolio of risky securities, given forecasts of future returns and an appropriate covariance matrix of share returns.[4]

Sharpe (1963) attempted to simplify the process of data input, data tabulation, and reaching a solution. He also developed a simplified variant of the Markowitz model that reduces data and computational requirements. Although Markowitz model was theoretically elegant its serious limitation was the sophisticated and volume of work was well beyond the Markowitz model. [5] William Sharpe (1964) has given model known as Sharpe Single Index Model (SIM) which laid down some steps that are required for construction of optimal portfolios. [6] Elton, Gruber and Padberg (1976) suggested using single index model to avoid problems like difficulty in data input, educating portfolio managers and time-cost consideration. [7]

Bowen (1984) noted that the Markowitz model required large volumes of data and found that it was difficult to estimate large number of covariance. He doubted whether the predictions from the model would be reliable and concluded that 'semantic and statistical barriers exist that prevent the average businessman from coming to grips with the approach'.[8] Michaud (1989) said that Markowitz optimization is not used more in practice, despite its theoretical success due to the conceptually demanding nature of the theory; the fact that most investment companies are not structured to use a mean-variance optimization approach; and Anecdotal evidence that portfolio managers find the composition of optimized portfolios counter-intuitive.[9] Haugen and Baker (1990) concluded that superior tracking ability in the estimation period does not necessarily imply superior predictive power in future periods. And Markowitz model has remarkably high predictive power, at least in tracking annual inflation. [10] Bodie, Kane and Marcus (2005) stated that portfolio mathematics and the theory of Markowitz minimum-variance frontier is well documented. [11] Plessis and Ward (2009) stated that Markowitz optimal portfolio does provide the basis of a useful trading rule strategy. [12]

As seen by Frankfurter et al. (1976) the SIM approach is based on Markowitz model. However, this approach adds the simplifying assumption that returns on various securities is related only through common relationship with some basic underlying factors. According to this study, under conditions of certainty, the Markowitz and SIM approaches will arrive at the same decision set in the experiment. These results demonstrate that under conditions of uncertainty, SIM approach is advantageous over the Markowitz approach. It was found that variation in performance is explained in terms of the two essential differences in the models. First, fewer and different estimators are used in the SIM model to summarize past history. Second, the linear assumption of the SIM model does not necessarily hold. [13]

Affleck-Graves and Money (1976) concluded that the Markowitz approach produces results which are significantly superior to those obtained using an index model. Thus, in practice, the investor wishing to use a risk-return approach to portfolio selection should strive to apply the basic Markowitz formulation. If this is impossible, an index model may be used, but it is stressed that the results obtained may be overly conservative. However, if the total amount to be invested is very large, thus forcing a low upper bound to be imposed on the amount invested in any security, then the index models may be used with much more confidence. [14] 
Omet (1995) argued that the two models are similar. SIM model can be used, which is more practical than the Markowitz model in generating ASE efficient frontier. [15] According to Terol et al. (2006) Markowitz model is a conventional model proposed to solve the portfolio selection problems by assuming that the situation of stock markets in the future can be characterized by the past asset data. However, it is difficult to ensure the accuracy of this traditional assuming because of the large number of extensions to problems of the traditional portfolio selection. As for SIM model, it includes fuzzy betas obtained not only from statistical data but also from expert knowledge. [16] In addition, Briec \& Kerstens (2009) stated that Markowitz model contributes in geometric mean optimization advocated for long term investments. On the other hand, the SIM models are no longer good approximations to multi period. [17]

\subsection{Data Source}

\section{Methodology And Data}

This paper aims at constructing an optimal portfolio by using Sharpe's single-index model. For this purpose monthly closing price of the shares, dividend information and monthly closing index value of the benchmark market index (DSE all share price index) have been used for the period from July 2007 to June 2012. They were collected from Dhaka Stock Exchange. This study takes 164 companies listed in Dhaka Stock Exchange (DSE). The study has used secondary data because it pertains to historical analysis of reported financial data. Auction of 91 days Treasury bill has been used as proxy for risk-free rate sourced from "Bangladesh Bank". The collected data were consolidated as per study requirements. Various statistical tools have been used to analyze data through Microsoft Excel software.

\subsection{Methodology}

The research methodology is centered on the application of Markowitz model. The basic portfolio model was developed by Harry Markowitz $(1952,1959)$, who derived the expected rate of return for a portfolio of assets and an expected risk measure. Markowitz showed that the variance of the rate of return was a meaningful measure of portfolio risk under a restorable set of assumptions, and he derived the formula for computing the variance of a portfolio. This portfolio variance formula not only indicated the importance of diversifying investments to reduce the total risk of a portfolio but also showed how to effectively diversify. [2]

To analyze return and risk characteristic of the stocks, the monthly mean return and standard deviation are calculated. And dividend information is incorporated with the monthly closing price. The monthly return on each stock is calculated as follows:

$$
R_{i t}=\frac{p_{i t}}{p_{i t-1}}-1
$$

Where $R_{i t}$ is the monthly return on stock $i$ at time $t ; P_{i t}$ is the adjusted monthly closing price of the stock $i$ at time $t$; and $p_{i t-l}$ is the adjusted monthly closing price of the stock $i$ at time $t-1$.

The expected return on each stock is calculated as follows:

$$
E\left(R_{i}\right)=\frac{\sum_{i=1}^{n} R_{i}}{n}
$$

The risk on each stock is calculated as follows:

$$
\sigma_{i}=\sqrt{\frac{\sum_{i=1}^{n}\left(R_{i}-E\left(R_{i}\right)\right)^{2}}{n}}
$$

A single asset or portfolio of assets is considered to be efficient if no other asset or portfolio of assets offers higher expected return with the same ( or lower) risk or lower risk with the same (or higher) expected return.

The expected return on a portfolio is calculated as follows:

$$
E\left(R_{p}\right)=\sum_{i=1}^{n} X_{i} E\left(R_{i}\right)
$$

Where $X_{i}$ is the fraction of investment in stock $i$ and $E\left(R_{i}\right)$ is the expected rate of return on stock $i$.

The risk of a portfolio can be written as: 


$$
\sigma_{p}^{2}=\sqrt{\sum_{i=1}^{n}\left(X_{i}^{2} \sigma_{i}^{2}\right)+\sum_{\substack{i=1 \\ j}}^{n} \sum_{\substack{j=1 \\ i \neq j}}^{n}\left(X_{i} X_{j} \sigma_{i j}\right)}
$$

$$
\begin{array}{cc}
\text { The covariance between } \\
\sigma_{i j}=\sigma_{i} \sigma_{j} \rho_{i j} & \text { securities } i \text { and } j \text { can be written as: }
\end{array}
$$

Where $\rho_{i j}$ is the correlation coefficient between securities $i$ and $j$.

The efficient set is determined by finding that portfolio with the greatest ratio of excess return (expected return minus risk- free rate) to standard deviation that satisfies the constraint that the sum of the proportions invested in the assets equals 1 . Here $11.25 \%$ p. a is considered as risk free rate, $R_{f}$ based on the 91 days treasury bills rate. In equation form we have:

$$
\theta=\frac{E\left(R_{p}\right)-R_{f}}{\sigma_{p}}
$$

Maximize the objective function subject to the constraint [18]

$$
\begin{aligned}
& \text { 1. } \sum_{i=1}^{n} X_{i}=1 \\
& \text { 2. } \sum_{i=1}^{n}\left(X_{i}-E\left(R_{i}\right)\right)=E\left(R_{p}\right) \\
& \text { 3. } X_{i} \geq 0, \quad i=1,2, \ldots, n
\end{aligned}
$$

This is a constrained maximization problem. To solve this problem Solver Parameters is used here.

\section{Data Analysis And Findings}

For constructing an optimal portfolio, a sample size of 164 companies is selected from the securities listed on Dhaka Stock Exchange (DSE). DSE all share price index is taken as the market index. Monthly closing price of these securities is used for the period from July 2007 to June 2012. They are collected from DSE. The return on riskless rate is considered as 11.25\%p.a (91 days Treasury bill) sourced from "Bangladesh Bank".

Table 1: Sector-wise Percentage of Data Coverage

\begin{tabular}{|l|c|c|c|}
\hline \multicolumn{1}{|c|}{ Name of the Industry } & $\begin{array}{c}\text { Total Number of } \\
\text { Companies }\end{array}$ & No. of Companies & $\begin{array}{c}\text { \% of Data } \\
\text { Coverage }\end{array}$ \\
\hline Bank & 30 & 27 & $90.00 \%$ \\
\hline Financial Institutions & 22 & 13 & $59.09 \%$ \\
\hline Engineering & 23 & 18 & $78.26 \%$ \\
\hline Food \& Allied & 16 & 9 & $56.25 \%$ \\
\hline Fuel \& Power & 14 & 7 & $50.00 \%$ \\
\hline Jute & 3 & 1 & $33.33 \%$ \\
\hline Textile & 26 & 17 & $65.38 \%$ \\
\hline Pharmaceuticals \& Chemicals & 20 & 14 & $70.00 \%$ \\
\hline Paper \& Printing & 1 & 1 & $100.00 \%$ \\
\hline Services \& Real Estate & 4 & 2 & $50.00 \%$ \\
\hline Cement & 6 & 4 & $66.67 \%$ \\
\hline IT - Sector & 6 & 4 & $66.67 \%$ \\
\hline Tannery Industries & 5 & 4 & $80.00 \%$ \\
\hline Ceramic Industry & 5 & 3 & $60.00 \%$ \\
\hline Insurance & 45 & 32 & $71.11 \%$ \\
\hline Miscellaneous & 9 & 8 & $88.89 \%$ \\
\hline \multicolumn{1}{|c|}{ Total } & $\mathbf{2 3 5}$ & $\mathbf{1 6 4}$ & $\mathbf{6 9 . 7 9 \%}$ \\
\hline
\end{tabular}

From the table 1 it can be seen that among 235 companies 164 companies are selected due to the reason of the availability of data within the time frame (July 2007 to June 2012). It has covered $69.79 \%$ data and it can be said that data coverage is moreover satisfactory to make an investment decision. 
Table 2: Result of Optimal Portfolio from Selected Companies (July 2007 to June 2012)

\begin{tabular}{|c|c|c|c|c|}
\hline No. & Name of Company & $\begin{array}{c}\text { Weight of } \\
\text { Securities }(\%)\end{array}$ & $\mathbf{E}\left(\mathbf{R}_{\mathbf{i}}\right)$ & $\sigma \mathbf{i}$ \\
\hline 1 & BATBC & $19.34837 \%$ & $4.63 \%$ & $14.28 \%$ \\
\hline 2 & Bata Shoe & $18.57291 \%$ & $6.00 \%$ & $17.20 \%$ \\
\hline 3 & Fine Foods Limited & $14.34212 \%$ & $8.12 \%$ & $26.14 \%$ \\
\hline 4 & Lankabangla Finance Ltd. & $13.96271 \%$ & $4.54 \%$ & $20.26 \%$ \\
\hline 5 & Metro Spinning & $5.40940 \%$ & $8.64 \%$ & $44.34 \%$ \\
\hline 6 & Beach Hatchery Ltd. & $5.14936 \%$ & $10.46 \%$ & $40.61 \%$ \\
\hline 7 & Janata Insurance & $4.41557 \%$ & $8.91 \%$ & $41.48 \%$ \\
\hline 8 & Pharma Aids & $4.11603 \%$ & $11.60 \%$ & $64.58 \%$ \\
\hline 9 & Power Grid Company of Bangladesh Ltd. & $2.92395 \%$ & $4.88 \%$ & $45.13 \%$ \\
\hline 10 & Padma Oil Co. & $2.58827 \%$ & $6.35 \%$ & $31.67 \%$ \\
\hline 11 & IDLC & $2.37212 \%$ & $4.63 \%$ & $28.88 \%$ \\
\hline 12 & Al-Haj Textile & $1.52385 \%$ & $9.18 \%$ & $67.06 \%$ \\
\hline 13 & CMC Kamal & $1.40387 \%$ & $7.95 \%$ & $37.32 \%$ \\
\hline 14 & Meghna Pet Industries & $1.13576 \%$ & $4.48 \%$ & $21.22 \%$ \\
\hline 15 & City Bank & $0.71000 \%$ & $2.30 \%$ & $30.38 \%$ \\
\hline 16 & IFIC Bank & $0.71000 \%$ & $1.43 \%$ & $29.25 \%$ \\
\hline 17 & Islami Bank & $0.71000 \%$ & $0.99 \%$ & $24.47 \%$ \\
\hline 18 & Prime Finance \& Invest. & $0.36051 \%$ & $4.36 \%$ & $28.16 \%$ \\
\hline 19 & Bd. Welding Electrodes & $0.24510 \%$ & $9.23 \%$ & $40.98 \%$ \\
\hline 20 & Fu-Wang Ceramic & $0.00001 \%$ & $3.93 \%$ & $24.96 \%$ \\
\hline & $\begin{array}{c}\text { Theta } \\
\end{array}$ & \multicolumn{3}{|c|}{0.4696} \\
\hline & Portfolio Return & \multicolumn{3}{|c|}{$6.48 \%$} \\
\hline & Portfolio Risk & \multicolumn{3}{|c|}{$11.79 \%$} \\
\hline
\end{tabular}

Table 2 clearly explains the results of empirical analysis. A model was developed in Microsoft Excel and Solver Parameters was used for the mean-variance optimization required to identify Markowitz efficient frontier. If short sale is not allowed, it is seen that the optimum portfolio consists of only 20 securities with the largest investment in British American Tobacco Bangladesh Co. Ltd. (BATBC) and the smallest in Fu-Wang Ceramic Industry Limited. Portfolio return and portfolio risk have found out respectively $6.48 \%$ and $11.79 \%$. The efficient set is determined by finding that portfolio with the greatest ratio of excess return to standard deviation (here theta is 0.4696) that satisfies the constraint that the sum of the proportions invested in the assets equals 1 . Such portfolio is the optimum portfolio and the securities included in the portfolio are the efficient securities. In a diversified portfolio, some securities may not perform as expected but others may exceed the expectation to the anticipated one. Higher number of negative covariance indicates more diversification power. Here the number of covariance will be $n(n-1) / 2=20(20-1) / 2=190$. In case of no-short sale scenario, the study has shown 30 numbers of negative covariance that is moreover satisfactory to realize the diversification effect as well as to maximize excess return to standard deviation ratio.

\section{Conclusion}

Risk and return play an imperative role in making any investment decisions. This study aims at analyzing the opportunity that are available for investors as per as returns are concerned and the investment of risk thereof while investing in equity of firms listed in the Dhaka stock exchange. Markowitz model was applied by using the monthly closing prices of 164 companies listed in DSE and DSE all share price index for the period from July 2007 to June 2012. From the empirical analysis, it can be said that data coverage of this paper is moreover satisfactory to make an investment decision because it covers $69.79 \%$ of data. Out of 164 companies taken for the study, 23 companies are showing negative returns and the other 157 companies are showing positive returns. Out of 164 companies, 23 companies offer lower return than risk less rate, indicate that the investments in these stocks are irrational. Markowitz model implementation is much more time-consuming and more complex by the number of estimates required. The study that follows 164 stocks needs 13366 number of covariance. The sheer number of inputs is staggering. Recognition of this has motivated the search for the development of models. From this empirical analysis, to some extent one can able to forecast individual 
security's return through the market movement and can make use of it. And it is seen that based on this study if any investors construct their portfolio, it offers more than the expected return. So it may be concluded that Markowitz Model performs well in Dhaka Stock Exchange as well as Bangladesh Stock Market.

\subsection{Limitations of the Research}

This paper attempts to construct an optimal portfolio by using Markowitz model and thereby helps to make investment decisions. The current study however has some limitations. This study did not take into consideration the companies that are not listed on the DSE and the companies that are listed and traded but stopped operations. This study used monthly data rather than daily data. This study has successfully constructed an optimal portfolio consisting of 20 securities among various sectors; future research may concentrate on portfolio selection models and the development of new portfolio selection models and policies.

\section{References}

[1] H. Varian, A Portfolio of Nobel Laureates: Markowitz, Miller and Sharpe, The Journal of Economic Perspectives, 7(1), 1993, 159169.

[2] H. Markowitz, Portfolio Selection, Journal of Finance, 7(1), 1952, 77- 91

[3] H. Markowitz, Portfolio selection (John T. Wiley \& Sons, Inc., New York, 1959).

[4] J. Tobin, Liquidity Preference as Behavior Towards Risk, Review of Economic Studies, 25(1), 1958, 65-86.

[5] W. F. Sharpe, A Simplified Model for Portfolio Analysis, Management Science, 9(2), 1963, 277-293.

[6] W. F. Sharpe, Capital Asset Prices: A Theory of Market Equilibrium under Conditions of Risk, The Journal of Finance, Vol. 19, No. 3, 1964, 425-442.

[7] E. J.Elton, M. J Gruber, and M. W. Padberg, Simple Criteria for Optimal Portfolio Selection, The Journal of Finance, Vol. 31, Issue 5, 1976, 1341-1357.

[8] PA. Bowen, A hypothesis: Portfolio theory is elegant but useless, The Investment Analysts Journal, 24(2), 1984, 17-21.

[9] RO. Michaud, The Markowitz optimization enigma: Is 'optimized' optimal?, Financial Analysts Journal, 45(1), 1989, 31-42.

[10] R. A. Haugen and N. L Baker, Dedicated stock portfolios, The Journal of Portfolio Management, summer, 1990, 17-22.

[11] Z. Bodie, A. Kane, and A. J. Marcus, Investments (New York: McGraw-Hill. 2005).

[12] AD. Plessis and M. Ward, 2009, A note on applying the Markowitz portfolio selection model as a passive investment strategy on the JSE, Investment Analysts Journal, No. 69, 2009, 39-46.

[13] G.M. Frankfuter, F. Herbert, and J.P. Seagle, Performance of the Sharpe portfolio Selection model: a comparison, Journal of Financial \& Quantitative Analysis, 11(2), 1976, 195-204.

[14] J. F. Affleck-Graves and A. H. Money 1976, A comparison of two portfolio selection models, The Investment Analysts Journal, 7(4), 1976, 35-40.

[15] G. Omet, On the Performance of Alternative Portfolio Selection Models, Dirasat (The Humanities), 22(3), $1995,125-135$.

[16] A.B. Terol, B.P. Gladish, \& J.A. Ibias, Selecting the optimum portfolio using fuzzy compromise programming and Sharpe's singleindex model, Applied Mathematics and Computation, 182, 2006, 644-664.

[17] W. Briec \& K. Kerstens, Multi-horizon Markowitz portfolio performance appraisals: A general approach, Omega, 37, 2009, 50 62.

[18] J. Linter, The Valuation of Risk Assets and the Selection of Risky Investments in Stock Portfolios and Capital Budgets, Review of Economics and Statistics, XLVII, (Feb. 1965), 13-37. 